\title{
CNS Involvement in Chronic Inflammatory Demyelinating Polyneuropathy: A Visual Evoked Potential Study
}

\author{
Masanaka Takeda ${ }^{1 *}$, Hisao Tachibana ${ }^{2}$, Kenkichi Tuda ${ }^{1}$, Sayoko Wada ${ }^{1}$, Syuhei Kasama ${ }^{1}$, Shohei Watanabe ${ }^{1}$, Toshio Takaoka $^{1}$, Takashi $^{1}$ \\ Kimura ${ }^{1}$, Koji Kajiyama ${ }^{1}$ and Hiroo Yoshikawa ${ }^{1}$
}

${ }^{1}$ Neurology and Stroke Unit, Hyogo College of Medicine, 1-1 Mukogawa-cho, Nishinomiya, Hyogo 663-8501, Japan

${ }^{2}$ Division of General Medicine, Department of Internal Medicine, Hyogo College of Medicine, 1-1 Mukogawa-cho, Nishinomiya, Hyogo 663-8501, Japan

\begin{abstract}
The visual evoked potentials (VEPs) of 10 patients with chronic inflammatory demyelinating polyneuropathy (CIDP) and 25 normal subjects were studied to identify possible evidence of central nervous system (CNS) demyelination. VEPs were performed in each patient before and 1 month after treatment with intravenous immunoglobulins (IVIg). Prolonged P100 latency ( $\geq$ mean \pm 2 SD of normal subjects) in 3 patients $(30 \%)$ in at least one eye before IVIg treatment was improved in both eye stimulations after treatment. They also showed recovery of motor function after IVIg administration. MRI showed no lesions suggestive of CNS demyelination in any patients. Our findings suggest the existence of combined central and peripheral demyelinating lesions in CIDP and emphasize the possibility of a common pathogenic mechanism for both lesions.
\end{abstract}

Keywords: Chronic inflammatory demyelinating polyneuropathy (CIDP); Visual evoked potentials (VEPs); Intravenous immunoglobulins (IVIg); Central nervous system (CNS) involvement

\section{Introduction}

Chronic inflammatory demyelinating polyneuropathy (CIDP) is considered to be an autoimmune disorder of the peripheral nervous system. Central nervous system (CNS) involvement has been clinically observed in 5\% [1] and $8 \%[2]$ of patients and in many cases of CIDP, there is accompanying CNS demyelination with the presence of subclinical electrophysiological and magnetic resonance imaging (MRI) abnormalities [3-5]. In an attempt to investigate the possible existence of CNS demyelinating lesions in CIDP patients, we prospectively studied visual evoked potentials (VEPs) in 10 patients.

\section{Patients and Methods}

Ten patients $(61.1 \pm 16.9$ years, mean \pm SD) with CIDP, fulfilling the diagnostic criteria outlined by the Joint Task Force of the EFNS and the PNS [6] and 25 normal subjects (66.6 99.5 years) participated in this study. The clinical features of the patients are described in (Table 1). Age at examination ranged from 38 to 77 years $(61.1 \pm 16.9$ years) and duration of illness ranged from 4 months to 10 years. None of the patients had a history of CNS involvement. Clinical course was chronic progressive in 5 patients and relapsing-remitting in the remaining 5. Electrophysiological data were consistent with a demyelinating polyneuropathy and the etiology of the neuropathy was unknown. Patients with paraneoplastic disorders, monoclonal gammopathy, HIV, metabolic disorders, sarcoidosis, lupus erythematous, or angiitis were excluded. All patients underwent an ophthalmological examination to rule out refractive error and retinal lesions which may affect the VEP study. All patients had corrected visual acuity beyond 0.7 in each eye. CSF protein level was normal in 2 patients (20\%) but over $40 \mathrm{mg} / \mathrm{dl}$ in 8 patients (range $45-135 \mathrm{mg} / \mathrm{dl}$ ) without oligoclonal bands.

VEP studies were performed in all patients before and 2 and 4 weeks after treatment with intravenous immunoglobulins (IVIg). To record the VEPs, $\mathrm{Ag} / \mathrm{AgCl}$ electrodes were placed at $\mathrm{O} 1, \mathrm{Oz}$ and $\mathrm{O} 2$, referred to as $\mathrm{Fpz}$ in the international 10/20 system. Pattern reversal VEPs were elicited using a black and white checkerboard pattern on a TV screen. The screen was subtended at an angle of $17^{\circ}$ at the eyes and each check was subtended an angle of $1^{\circ}$. The mean luminance of the checkerboard was $50 \mathrm{~cd} / \mathrm{mm}^{2}$ with high contrast (60\%). Monocular stimuli were delivered at a frequency of $1 \mathrm{~Hz}$. The responses were amplified and potentials to 100 stimulations were averaged with the Neuropack MEB-2208 measurement system (Nihon-Koden, Japan). The filter window was $1-100 \mathrm{~Hz}$ and the analysis time was 200 ms. P100 responses to independent left and right eye stimulations were recorded at $\mathrm{O} 1, \mathrm{O} 2$ and $\mathrm{Oz}$. The P100 latency referred to the interval between the stimulus and the peak of the major positive components and the P100 amplitude referred to the peak-to-peak amplitude between N75 and P100 responses. The P100 latency and amplitude at $\mathrm{Oz}$ in response to left and right eye stimulation were used for comparison. Informed consent was obtained from all study participants.

\section{Results}

In the normal subjects, mean P100 latency and amplitude of the VEPs were $102.5 \pm 9.2 \mathrm{~ms}$ and $7.4 \pm 2.8 \mu \mathrm{V}$, respectively. More than $120.9 \mathrm{~ms}$ (mean+2SD) in P100 latency and less than $1.8 \mu \mathrm{V}$ $($ mean $+2 \mathrm{SD})$ in amplitude were considered to be abnormal. The results for P100 latency and amplitude of the VEPs for the 10 subjects are summarized in (Table 2). Compared with the controls, 3 patients (Nos. 2, 4 and 10) had increased P100 latency preoperatively in at least one eye, which was shortened (Figure 1) in both eyes after treatment with IVIg (Table 2). After the IVIg administration, muscle weakness and cranial nerve palsy improved in all 3 patients. On the other hand, in the other 7 patients (Nos. 1, 3, 5, 6, 7, 8 and 9) P100 latency was within normal range and remained unchanged after treatment with IVIg.

*Corresponding author: Masanaka Takeda, Neurology and Stroke Unit, Hyogo College of Medicine, 1-1 Mukogawa-cho, Nishinomiya, Hyogo 663-8501, Japan, Tel: +81-798-6598; Fax: +81-798-6597; E-mail: tmasa@hyo-med.ac.jp

Received November 03, 2010; Accepted November 20, 2010; Published November 22, 2010

Citation: Takeda M, Tachibana H, Tuda K, Wada S, Kasama S, et al. (2010) CNS Involvement in Chronic Inflammatory Demyelinating Polyneuropathy: A Visual Evoked Potential Study. J Neurol Neurophysiol 1:105. doi:10.4172/21559562.1000105

Copyright: @ 2010 Takeda M, et al. This is an open-access article distributed under the terms of the Creative Commons Attribution License, which permits unrestricted use, distribution, and reproduction in any medium, provided the original author and source are credited. 
Citation: Takeda M, Tachibana H, Tuda K, Wada S, Kasama S, et al. (2010) CNS Involvement in Chronic Inflammatory Demyelinating Polyneuropathy: A Visual Evoked Potential Study. J Neurol Neurophysiol 1:105. doi:10.4172/2155-9562.1000105

Page 2 of 3

\begin{tabular}{|c|c|c|c|c|c|c|c|c|c|c|}
\hline \multicolumn{11}{|c|}{ Clinical Symptoms } \\
\hline $\begin{array}{l}\text { Patient } \\
\text { No. }\end{array}$ & Sex & $\begin{array}{l}\text { Age at } \\
\text { onset (year) }\end{array}$ & $\begin{array}{l}\text { Age at } \\
\text { exam. (year) }\end{array}$ & $\begin{array}{l}\text { Duration (months } \\
\text { or years) }\end{array}$ & $\begin{array}{l}\text { CSF cells / protein } \\
\text { / ul ( /ul, mg/ dl) }\end{array}$ & $\begin{array}{l}\text { Clinical } \\
\text { course }\end{array}$ & $\begin{array}{l}\text { Response } \\
\text { to IVlg }\end{array}$ & $\begin{array}{l}\text { Predominant } \\
\text { symptoms }\end{array}$ & Clinical type & Other symptoms \\
\hline 1 & $M$ & 35 & 38 & $3 y$ & $1 / 135$ & $\mathrm{R}$ & + & motor > sensory & typical CIDP & double vision, dysarthria \\
\hline 2 & $M$ & 39 & 43 & $4 y$ & $2 / 45$ & $\mathrm{R}$ & + & motor $\geq$ sensory & typical CIDP & - \\
\hline 3 & $\mathrm{~F}$ & 33 & 43 & $10 y$ & $2 / 19$ & $\mathrm{R}$ & + & motor $\gg>$ sensory & MADSAM & - \\
\hline 4 & $\mathrm{~F}$ & 74 & 75 & $8 m$ & $7 / 70$ & $\mathrm{CP}$ & + & motor > sensory & typical CIDP & - \\
\hline 5 & $\mathrm{~F}$ & 76 & 77 & $1 \mathrm{y}$ & $2 / 66$ & $\mathrm{CP}$ & + & motor $\geq$ sensory & typical CIDP & double vision, ptosisb \\
\hline 6 & $\mathrm{~F}$ & 67 & 71 & $4 y$ & $1 / 29$ & $\mathrm{CP}$ & + & motor $=$ sensory & typical CIDP & numbness of face \\
\hline 7 & $\mathrm{M}$ & 75 & 76 & $4 m$ & $0 / 46$ & $\mathrm{R}$ & + & motor > sensory & MADSAM & - \\
\hline 8 & $\mathrm{~F}$ & 42 & 42 & $5 m$ & $5 / 65$ & $\mathrm{R}$ & + & motor > sensory & MADSAM & double vision, dysarthria ptosis \\
\hline 9 & $M$ & 74 & 75 & $5 \mathrm{~m}$ & $1 / 49$ & $\mathrm{CP}$ & + & motor >> sensory & typical CIDP & - \\
\hline 10 & $M$ & 65 & 70 & 5 & $1 / 129$ & $\mathrm{CP}$ & \pm & motor $=$ sensory & typical CIDP & - \\
\hline
\end{tabular}

$\mathrm{CP}$ : chronic progressive R: relapsing-remitting

MADSAM: multifocal acquired demyelinating sensory and motor

Table 1: Clinical characteristics of patients with CIDP.

\begin{tabular}{|c|c|c|c|c|}
\hline \multirow[t]{2}{*}{ Patient No. } & \multicolumn{2}{|c|}{ latency $(\mathrm{ms})(\mathrm{R} / \mathrm{L})$} & \multicolumn{2}{|c|}{ amplitude $(\mu \mathrm{v})(\mathrm{R} / \mathrm{L})$} \\
\hline & before IVIg & after IVIg & before IVIg & after IVIg \\
\hline 1 & $98.7 / 101.4$ & $86.4 / 90.5$ & $1.9 / 2.5$ & $2.8 / 2.9$ \\
\hline 2 & $121.2 * / 117.3$ & $111.0 / 112.8$ & $3.9 / 4.5$ & $4.5 / 3.5$ \\
\hline 3 & $94.8 / 98.2$ & $98.7 / 95.2$ & $6.6 / 9.5$ & $4.1 / 8.2$ \\
\hline 4 & $147.9^{*} / 146.7^{*}$ & $127.8^{*} / 125.7^{*}$ & $4.1 / 4.8$ & $10.3 / 10.2$ \\
\hline 5 & $97.5 / 101.7$ & 98.0/99.2 & $3.4 / 2.6$ & $5.6 / 2.5$ \\
\hline 6 & $94.2 / 98.1$ & $94.8 / 99.3$ & $8.0 / 10.9$ & $10.4 / 11.0$ \\
\hline 7 & $106.5 / 103.8$ & $103.5 / 98.7$ & $5.2 / 2.3$ & $5.1 / 4.5$ \\
\hline 8 & $95.4 / 95.1$ & $91.8 / 93.0$ & $8.3 / 11.6$ & $11.8 / 9.8$ \\
\hline 9 & $96.0 / 95.7$ & $98.1 / 99.0$ & $4.5 / 7.3$ & $10.3 / 8.9$ \\
\hline 10 & $126.9^{*} / 138.6^{*}$ & $115.2 / 120.0$ & $7.6 / 6.5$ & $6.5 / 6.3$ \\
\hline
\end{tabular}

R: right eye stimulation, L: left eye stimulation

*abnormal value

Table 2: P100 latency and amplitude in patients with CIDP and normal controls.

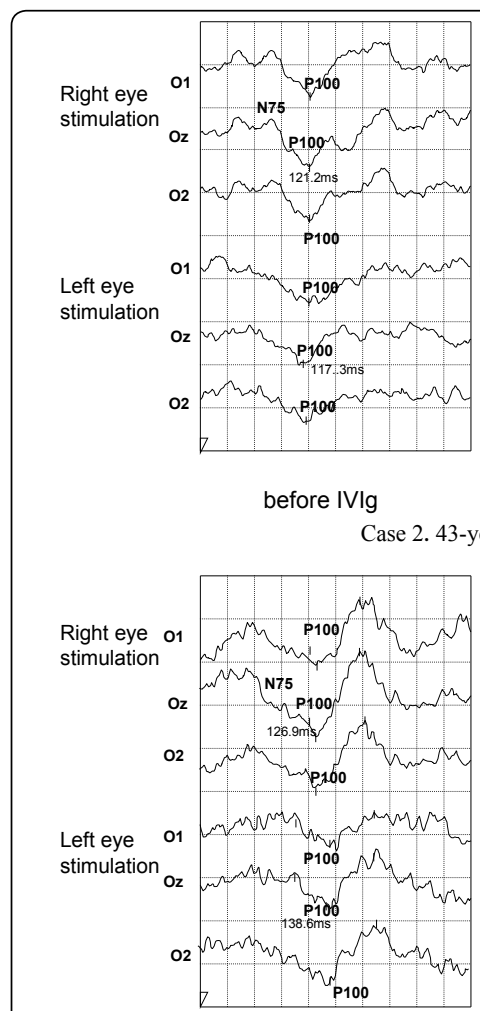

before IVIg

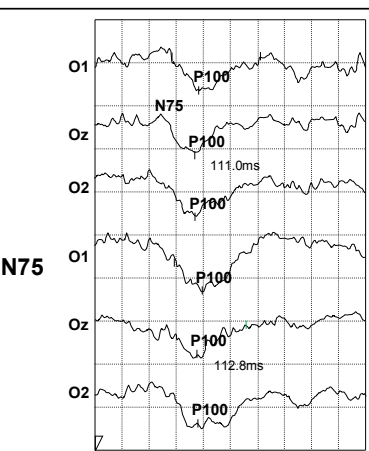

after IVIg

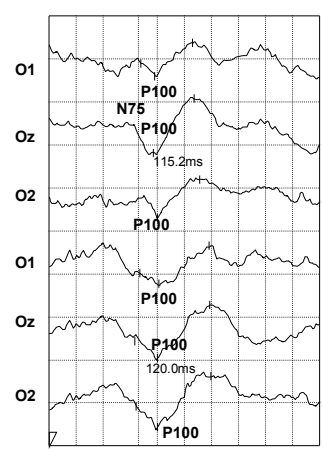

after IVIg

Case 4. 74-year-old female patient

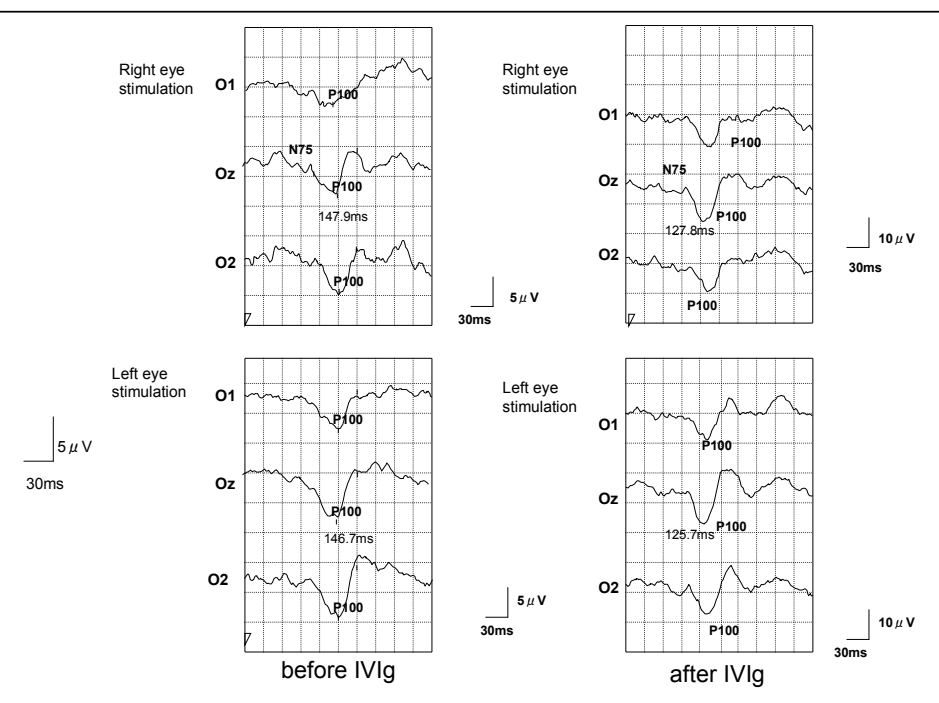

Case 10. 69-year-old male patient

Figure 1: VEPs of 3 cases with prolonged P100 latency before and after IVlg treatment. Prolonged P100 latency showed a trend to normal values in all 3 patients after IVIg treatment. 
Citation: Takeda M, Tachibana H, Tuda K, Wada S, Kasama S, et al. (2010) CNS Involvement in Chronic Inflammatory Demyelinating Polyneuropathy: A Visual Evoked Potential Study. J Neurol Neurophysiol 1:105. doi:10.4172/2155-9562.1000105

Page 3 of 3

\section{Discussion}

CIDP is an acquired, immune-mediated disease that targets the myelin sheaths of peripheral nerves. CIDP involves both demyelination and axonal degeneration, with the balance being determined by disease duration and severity [7]. Electrophysiological data of our CIDP patients were consistent with a demyelinating polyneuropathy. The present study revealed subclinical CNS involvement suggestive of demyelination in patients with CIDP by electrophysiological study. Our results are compatible with those of Pineda et al. [4], who indicated such subclinical CNS demyelination-involved CIDP patients more responsive to immunotherapies. Subclinical visual pathway abnormalities were demonstrated in $30 \%$ of our CIDP patients. Other authors have also demonstrated VEP abnormalities in CIDP patients, but at higher rates of $50 \%$ [8] or $85 \%$ [9]. Stojkovic et al. [10] studied 8 patients with CIDP who had increased VEP latency, although VEP results were not significantly modified after treatment with either steroid or IVIg. They concluded that the measurement of VEPs was a useful technique for the diagnosis of visual pathway involvement, but was of no value for monitoring the effect of treatment in CIDP patients. We concur with this finding, as CIDP patients with prolonged P100 latency in the present study had shorter VEP latency in both eyes after treatment with IVIg. Moreover, the VEP parameters in patients with CIDP showed overall improvement with IVIg therapy, further supporting that its administration may be effective even for CNS lesions in CIDP.

\section{Reference}

1. Bouchard C, Lacroix C, Plante V, Adams D, Chedru F, et al. (1999) Clinicopathologic findings and prognosis of chronic inflammatory demyelinating polyneuropathy. Neurology 52: 498-503.
2. Rotta FT, Sussman AT, Bradley WG, Ram Ayyar D, Sharma KR, et al. (2000) The spectrum of chronic inflammatory demyelinating polyneuropathy. J Neurol Sci 173: 129-139.

3. Ohtake T, Komori T, Hirose K, Tanabe H (1990) CNS involvement in Japanese patients with chronic inflammatory demyelinating polyradiculoneuropathy. Acta Neurol Scand 81: 108-112.

4. Pineda AA, Ogata K, Osoegawa M, Murai H, Shigeta $H$, et al. (2007) A distinct subgroup of chronic inflammatory demyelinating polyneuropathy with CNS demyelination and a favorable response to immunotherapy. J Neurol Sci 225: $1-6$.

5. Hengstman GJ, Schelhaas HJ, Zwarts MJ (2004) Auditory dysfunction in chronic inflammatory demyelinating polyradiculoneuropathy. Neurology 62 : 1446-1448.

6. Joint Task Force of the EFNS and the PNS (2005) European Federation of Neurological Societies / Peripheral Nerve Society Guideline on management of chronic inflammatory demyelinating polyradiculoneuropathy. Report of a joint task force of the European Federation of Neurological Societies and the Peripheral Nerve Society. J Peripher Nerv Syst 10: 220-228.

7. McCombe PA, Pollard JD, McLeod G (1987) Chronic inflammatory demyelinating polyradiculoneuropathy; a clinical and electrophysiological study of 92 cases. Brain 110: 1617-1630.

8. Pakalnis A, Drake Jr ME, Barohn RJ, Chakeres DW, Mendell JR (1988) Evoked potentials in chronic inflammatory demyelinating polyneuropathy. Arch Neurol 45: 1014-1016.

9. Uncini A, Gallucci M, Lugaresi A, Porrini AM, Onofrj M, et al. (1991) CNS involvement in chronic inflammatory demyelinating polyneuropathy: an electrophysiological and MRI study. Electromyogr Clin Neurophysiol 31: 365371.

10. Stojkovic T, Seze JD, Hurtevent JF, Arndt C, Beaume A, et al. (2000) Visual evoked potentials study in chronic idiopathic inflammatory demyelinating polyneuropathy. Clin Neurophysiol 111:2285-2291. 